\title{
Professor Edward S. Bordin (1913-1992)
}

\author{
Professor Emeritus Edward S. Bordin died August 24, 1992 in La Jolla, \\ California.
}

A native of Pennsylvania, Bordin studied at Temple University, where he received his B.S. and M.S. degrees. His graduate work at Ohio State led to a Ph.D. in 1942. Following 3 years in the U.S. Army, he joined the University of Minnesota briefly as an assistant professor of psychology, was an associate professor and director of the Student Counseling Center at Washington State College from 1946-1948, then came to Michigan in 1948 as an associate professor of psychology and chief of the Counseling Division, rising to professor in 1955 and continuing to serve as director of the Counseling Center for all but a few years of the following decades.

Professor Bordin was a crucial member of the Department of Psychology and often served as chair of the doctoral program in clinical psychology and its interrelated counseling psychology program, helping build its stature to one of the nation's most highly regarded programs. Simultaneously, he shaped the Counseling Center for many years into a uniquely successful training, research, and student service center. Generations of graduate clinical students, many now in leadership roles across the country, profited not only from his intellectual stimulation and keen critical mind but also from working with a mentor who was such a striking model of clinicians' need to act amidst ambiguity, balancing clinical commitment and scientific skepticism.

His scholarship, perspective, wise judgment, and leadership were recognized and repeatedly sought outside the university as well. He served as editor of the Journal of Consulting Psychology. In the American Psychological Association, he played key roles in such positions as chair of the Board of Professional Affairs, president of the Division of Counseling Psychology; he was also a member of the Executive Committee of the Division of Clinical Psychology, of the Council of Representatives, and of the Policy and Planning Board. So too, he served on the National Institute of Mental Health's Clinical Program Research Review Committee, on the American Board of Examiners in Professional Psychology, and most recently as president of the Society for Psychotherapy Research. 
His scholarly interests, as his research and publication, have been wideranging and varied and have left an indelible mark on the field. He and a group of collaborating graduate students convincingly demonstrated the relationship of personality development to occupational choice. In another line of work, he drew up a masterful blueprint for psychotherapy research in his celebrated Research Strategies in Psychotherapy and launched the productive and influential Psychotherapy Research Project. Although others have dealt almost exclusively with treatment outcome studies, Professor Bordin focused on dissecting the multiple variables whose configurations and interactions in the therapeutic process differentially led to and account for treatment outcome.

-Albert C. Cain

University of Michigan 